\title{
Health Care Utilization and Cost Associated with Biologic Treatment Patterns Among Patients with Moderate to Severe Psoriasis: Analyses from a Large U.S. Claims Database
}

\author{
Steven R. Feldman, MD, PhD; Haijun Tian, PhD; Xinyue Wang, MS; and Rebecca Germino, PhD
}

\begin{abstract}
BACKGROUND: Discontinuation or switching of biologic treatment among patients with psoriasis imposes a great economic burden.

OBJECTIVE: To assess the health care utilization and costs associated with nonswitchers, switchers, and discontinuers of biologics among patients with moderate to severe psoriasis.
\end{abstract}

METHODS: Patients aged $\geq 18$ years with $\geq 1$ pharmacy claim for a biologic (adalimumab, etanercept, infliximab, and ustekinumab) between January 1, 2012, and June 30, 2015 (identification period), were identified in the Truven Health Analytics MarketScan Commercial and Medicare Supplemental databases. At the time of biologic initiation (index date), eligible patients were continuously enrolled with medical and pharmacy claims for $\geq 1$ year before (baseline period) and $\geq 1$ year after the index date (follow-up period). Patients had $\geq 1$ psoriasis diagnosis and had no pharmacy claims for the index biologic during the baseline period. Patients were categorized into 3 mutually exclusive groups based on their biologic treatment pattern during the 1-year follow-up period: nonswitchers (patients who remained on their index biologic), switchers (patients who had a prescription for a biologic therapy other than their index biologic), and discontinuers (patients who had gaps in prescription claims [ $>90$ days for adalimumab, infliximab, and etanercept; $>120$ days for ustekinumab]). Descriptive analyses were used to summarize baseline patient demographics, clinical characteristics, resource utilization, and health care costs (inflated to 2016 costs) across the 3 groups. Adjusted health care resource utilization and costs during the 1-year follow-up were estimated, controlling for age, sex, geographic region, insurance plan type, index drug, index year, Charlson Comorbidity Index score, resource utilization, total health care costs, and nonbiologic medications during the baseline period.

RESULTS: Of the 8,710 patients with psoriasis included in the study, 5,000 $(57.4 \%)$ were categorized as nonswitchers, 1,001 (11.5\%) as switchers, and $2,709(31.1 \%)$ as discontinuers. Emergency department and inpatient visits, respectively, were more common among switchers (adjusted incidence rate ratio [95\% $\mathrm{Cl}]: 1.10$ [0.93-1.30] and 1.13 [0.84-1.53]) and discontinuers (1.50 [1.34-1.63] and 2.05 [1.70-2.48]) than among nonswitchers. Compared with nonswitchers, switchers had higher adjusted mean total health care costs (mean difference [95\% Cl]: \$10,120 [\$8,235-\$12,033]), which were driven by increased prescription costs $(\$ 8,988[\$ 7,535-\$ 10,610])$ and medical costs $(\$ 2,746[\$ 1,090-\$ 4,677])$. Conversely, the adjusted mean total health care cost for discontinuers was lower than that for nonswitchers (mean difference $[95 \% \mathrm{CI}]:-\$ 18,611[-\$ 20,254,-\$ 17,025])$ due to reduced prescription costs $(-\$ 20,486[-\$ 21,319,-\$ 19,636])$; however, discontinuers had a higher mean medical cost $(\$ 3,729$ [\$1,970-\$5,527]).

CONCLUSIONS: Switching or discontinuing biologics resulted in higher health care utilization and increased medical costs than remaining on the same biologic. These updated findings highlight the clinical and economic effects of discontinuing or switching biologic therapies in patients with psoriasis in clinical practice and may inform treatment and/or formulary decision making.

J Manag Care Spec Pharm. 2019;25(4):479-88

Copyright $\odot 2019$, Academy of Managed Care Pharmacy. All rights reserved.

\section{What is already known about this subject}

Of the biologic therapies approved for moderate to severe psoriasis in the United States, tumor necrosis factor inhibitors (adalimumab, etanercept, infliximab) and the interleukin-12/23 inhibitor ustekinumab represent options that have been available the longest and with which dermatologists have the most experience using in clinical practice.

Patients may discontinue or switch therapies in clinical practice due to inadequate treatment response, adverse events, and/or lack of insurance coverage.

- Few studies have retrospectively identified treatment patterns with biologics in patients with moderate to severe psoriasis, and existing studies have provided limited updated evidence on health care resource utilization and costs associated with switching or discontinuing biologics reflective of treatments currently used in clinical practice.

\section{What this study adds}

Within 1 year of initiating a biologic (adalimumab, etanercept, infliximab, or ustekinumab) in this updated retrospective analysis of U.S. administrative claims data, $11.5 \%$ of patients with moderate to severe psoriasis switched from their index biologic to a new therapy; $31.1 \%$ discontinued their index biologic; and $57.4 \%$ remained on their index biologic.

Switching or discontinuing biologics during a 1-year follow-up period resulted in higher health care resource utilization (hospitalizations, emergency department visits, and outpatient visits) compared with remaining on the same biologic.

Compared with nonswitchers, switchers had higher total health care costs, which were driven by increased prescription and medical costs; discontinuers had lower total health care costs due to reduced prescription costs related to early discontinuation of therapy. 
$\mathrm{P}$ soriasis is a chronic, immune-mediated disease that affects approximately 7.4 million adults (2\%-4\%) in the United States; men and women are affected at approximately equal rates. ${ }^{1-6}$ Patients with psoriasis can experience significant physical, psychosocial, and economic health burdens that negatively affect their health-related quality of life. Psoriasis poses a substantial economic burden because it requires lifelong care and often continuous treatment. ${ }^{7-9}$ In the United States, the aggregated total annual estimated cost associated with psoriasis is between $\$ 112$ and $\$ 135$ billion. ${ }^{6}$ Patients with psoriasis also experience several comorbidities, including cardiovascular disease, metabolic syndrome, and depression, as well as poor self-esteem, anxiety, and decreased quality of life-all of which complicate management of the disease.

The American Academy of Dermatology guidelines for the management of psoriasis recommend biologics for patients who have moderate to severe psoriasis. ${ }^{1}$ Currently approved biologics for psoriasis in the United States include the tumor necrosis factor inhibitors (TNFis) adalimumab, etanercept, and infliximab; the interleukin (IL)-12/23 inhibitor ustekinumab; the IL-23 inhibitors guselkumab and tildrakizumab; the IL-17A inhibitors secukinumab and ixekizumab; and the IL-17RA inhibitor brodalumab., ${ }^{1,10-32}$ Of these, adalimumab, etanercept, infliximab, and ustekinumab have been approved since 2009 or earlier and represent biologic options with which clinicians have the most experience using for the treatment of moderate to severe psoriasis. Biologic agents have revolutionized the treatment of psoriasis in patients previously resistant to systemic therapies; however, biologics are more costly, and some patients may discontinue or switch therapies for a variety of reasons. ${ }^{33-35}$ Based on a recent retrospective study of a U.S. health claims database, $12.5 \%$ of patients with psoriasis switched therapy and 30.8\% discontinued therapy within the first year of initiating the biologics etanercept, adalimumab, and ustekinumab. ${ }^{36}$ The overall persistence rate of biologics for the 1-year follow-up period was $34.6 \%$, suggesting that most patients experienced medication disruptions.

It is helpful to understand the outcomes and economic effect of switching or discontinuing biologics in patients with psoriasis. A few retrospective analyses from U.S. claims data have been conducted to characterize treatment patterns, including switch patterns in patients with moderate to severe psoriasis $^{37-40}$; however, limited evidence exists regarding the effects of switching biologics on health care resource utilization and costs in these patients. Previous analyses using a large U.S. claims database examining data from 2008-2013 showed that patients with psoriasis who switched from TNFis (etanercept, adalimumab, infliximab) and ustekinumab had significantly higher health care utilization and costs than did those remaining on the same biologic. ${ }^{41,42}$ An updated analysis of the same treatments using more recent data is important given the existence of newly available biologics and tighter formularies, the results of which would be useful in addressing payer compensation questions in the United States. Because etanercept, adalimumab, infliximab, and ustekinumab have been available the longest in U.S. clinical practice compared with newer biologic therapies, patients initiating these biologics comprise the largest sample sizes of possible treatment populations. Furthermore, inclusion of a larger patient population allows for more clinically meaningful and detailed analyses to be conducted. The purpose of this study was to compare health care utilization and costs of switching or discontinuing biologics compared with remaining on index biologic therapy during 1 year of follow-up among patients with moderate to severe psoriasis.

\section{Methods}

\section{Study Design and Patient Population}

A retrospective cohort study was conducted using the Truven Health Analytics MarketScan Commercial Claims and Encounters Database (CCAE) and the Medicare Supplemental and Coordination of Benefits Database (MDCR) from January 1 , 2011-June 30, 2016. The CCAE and MDCR include fully adjudicated deidentified commercial health insurance claims (inpatient and outpatient medical and outpatient pharmacy) linked to enrollment data provided by larger employer-sponsored health plans across the United States.

Patients aged $\geq 18$ years with $\geq 1$ pharmacy claim for a biologic (adalimumab, etanercept, infliximab, and ustekinumab; see Appendix A, available in online article) from January 1 , 2012-June 30, 2015 (identification period), were identified in the Truven Health Analytics MarketScan CCAE and MDCR databases. Eligible patients at the time of biologic initiation (index date) were continuously enrolled, had medical and pharmacy claims for $\geq 1$ year before (baseline period) and $\geq 1$ year after the index date (follow-up period), and had $\geq 1$ psoriasis diagnosis (International Classification of Diseases, Ninth Revision, Clinical Modification [ICD-9-CM] code 696.1) during the baseline period. Exclusion criteria included diagnoses for which biologics are also indicated, such as rheumatoid arthritis (ICD-9-CM codes 714.0, 714.1, 714.2, 714.4, 714.81), ankylosing spondylitis (ICD-9-CM code 720.0), Crohn's disease (ICD-9-CM codes 555, 555.0, 555.1, 555.2, 555.9), or ulcerative colitis (ICD-9-CM codes 556, 556.0, 556.1, 556.2, 556.3, 556.4, $556.5,556.6,556.8,556.9)$, and pharmacy claims for the index biologic during the baseline period (Figure 1). Additionally, the treatment washout period of 1 year allowed for a reduction in bias introduced by prevalent biologic use.

Use of the CCAE and MDCR databases for health services research complies with the Health Insurance Portability and Accountability Act and federal guidance on public welfare and the protection of human subjects. 


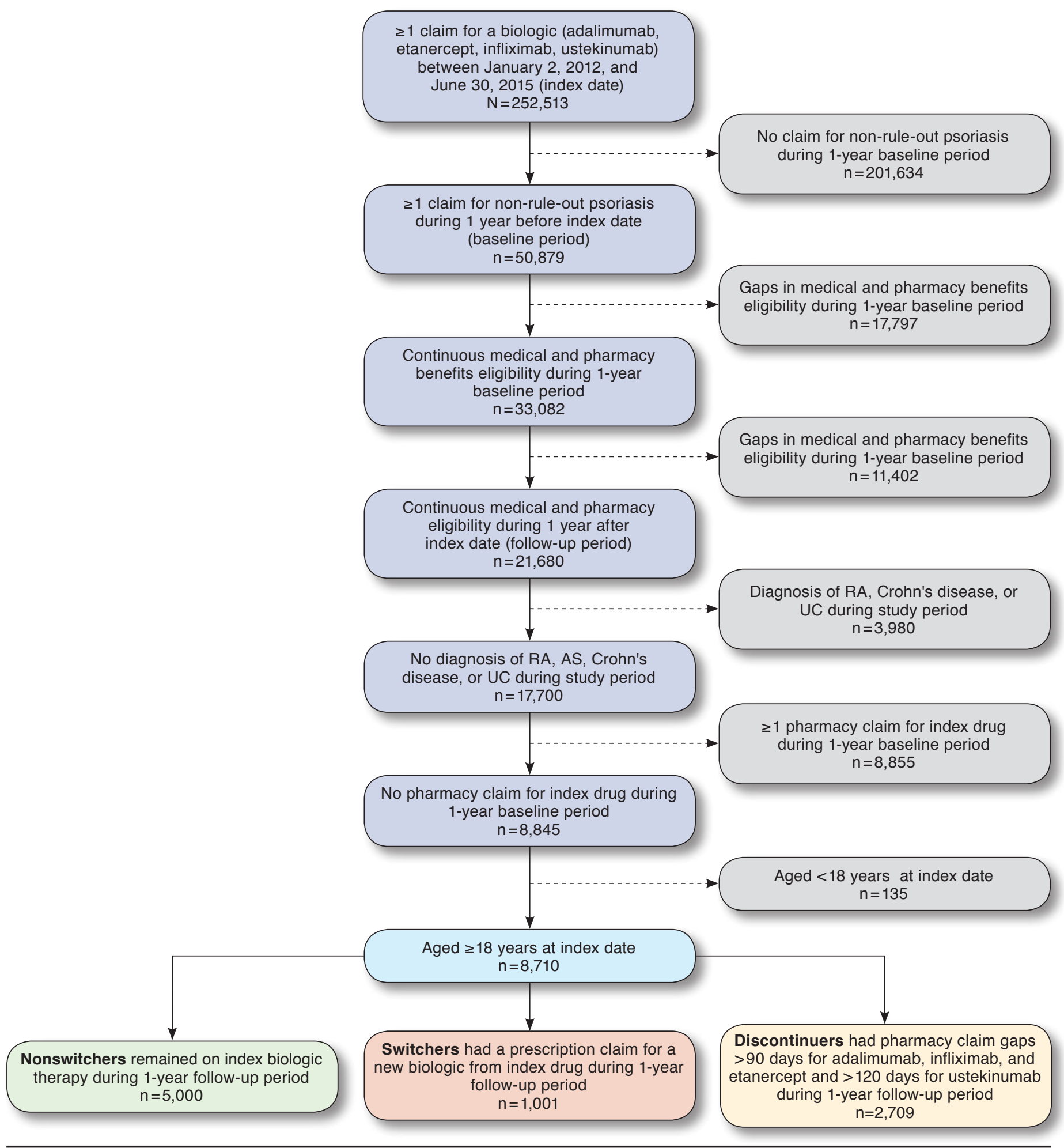

${ }^{a}$ Dashed lines represent exclusion criteria.

$A S=$ ankylosing spondylitis; $R A=$ rheumatoid arthritis; $U C=$ ulcerative colitis. 


\section{Study Variables}

Patients were categorized into 3 mutually exclusive groups based on their biologic treatment patterns during the 1-year follow-up period:

- Nonswitchers: Patients who remained on the index biologic during the 1-year follow-up period with no gaps in treatment.

- Switchers: Patients who had a prescription claim for a different biologic therapy (adalimumab, certolizumab pegol, etanercept, golimumab, infliximab, secukinumab, ustekinumab) than the index biologic and who switched therapies before permissible treatment gaps were reached ( $>90$ days for adalimumab, infliximab, and etanercept; > 120 days for ustekinumab).

- Discontinuers: Patients who had prescription claim gaps (time from exhaustion of previous days supply) during the 1-year follow-up period ( $>90$ days for adalimumab, infliximab, and etanercept; >120 days for ustekinumab). Discontinuers were further categorized as reinitiators or new initiators (defined as patients who had a prescription claim for the same or different biologic therapy, respectively, after the permissible treatment gap cutoffs) or as pure discontinuers (defined as patients who did not have any prescription claims for biologic therapy during the 1-year follow-up period).

- As a secondary analysis, the time to initiation of new therapy was described for the subset of discontinuers classified as new initiators to better assess the effect of additional prescription costs on total health care costs for the overall discontinuers group.

Patient demographics (age, sex, employment status, insurance plan type, and geographic location) were assessed at the index date; clinical characteristics (Charlson Comorbidity Index [CCI] score and comorbidities), medication history (index biologic therapy [adalimumab, etanercept, infliximab, and ustekinumab] and nonbiologic medications [apremilast, acitretin, cyclosporine, and methotrexate]), all-cause health care resource utilization (hospitalizations, emergency department [ED] visits, and outpatient visits), and all-cause health care costs (including medical [inpatient, outpatient, and ED costs] and prescription drug costs) were measured during the 1 -year baseline period. The CCI is a validated risk adjustment tool that is widely used to categorize patient comorbidities and predict outcomes such as mortality and health care resource utilization in administrative data. ${ }^{43}$ It includes 17 medical conditions based on their respective ICD-9-CM codes and assigns a weight of 1-6 to each condition based on their association with the risk of the outcome; the sum of all weights is combined to a single score for a patient. All medical conditions in the study were defined using ICD-9-CM codes and were identified from literature..$^{43}$ All-cause health care resource utilization and health care costs were calculated as per patient per year; health care costs were inflated to year 2016 costs. All-cause health care resource utilization and health care costs were measured during the 1-year follow-up period.

\section{Data Analysis}

Descriptive statistics were tabulated for patient characteristics and outcome variables (health care resource utilization and costs) comparing nonswitchers versus switchers and nonswitchers versus discontinuers. Bivariate analyses were conducted to compare all baseline characteristics across treatment pattern groups. Comparisons across treatment pattern groups were made using chi-squared tests for categorical variables and Wilcoxon rank-sum tests or unequal variance 2-sample t-test for continuous variables.

Multivariable models were fitted to compare all-cause health care resource utilization and costs between switchers versus nonswitchers and discontinuers versus nonswitchers. Health care resource utilization was modeled using negative binomial regressions for inpatient visits and ED visits and Poisson regression for outpatient visits. Generalized linear regression with a log link and gamma distribution or 2-part models were used to model health care costs. For the 2-part models, logistic regression was used to model probabilities of positive costs followed by gamma regression to model costs among patients with positive costs. Adjusted costs were estimated for switchers, nonswitchers, and discontinuers based on the models, and 95\% confidence intervals (CIs) were obtained by nonparametric bootstrapping with 1,000 repetitions. All models were adjusted to control for baseline covariates, including age, sex, geographic regions, insurance plan types, index drug (adalimumab, etanercept, infliximab, and ustekinumab), index year, baseline CCI, baseline resource utilization, baseline total health care costs, and baseline nonbiologic medications. All analyses were done using SAS version 9.4, basic edition (SAS Institute, Cary, NC).

\section{Results}

This study included 252,513 patients with $\geq 1$ claim for etanercept, infliximab, adalimumab, or ustekinumab during the identification period between January 1, 2012, and June 30, 2015 After inclusion and exclusion criteria were applied, the final study cohort consisted of 8,710 patients with moderate to severe psoriasis who initiated a biologic (Figure 1). Overall, 4,289 patients (49.2\%) initiated adalimumab (56.8\% nonswitchers, $12.7 \%$ switchers, and 30.5\% discontinuers); 2,795 (32.1\%) initiated etanercept (52.2\% nonswitchers, $12.8 \%$ switchers, and $35.0 \%$ discontinuers); 161 (1.8\%) initiated infliximab (62.1\% nonswitchers, $15.5 \%$ switchers, and $22.4 \%$ discontinuers); and 1,465 (16.8\%) initiated ustekinumab (68.7\% nonswitchers, $5.1 \%$ switchers, and $26.3 \%$ discontinuers; Table 1). 
TABLE 1 Overview of Biologic Treatment Pattern Subgroups in Patients with Moderate to Severe Psoriasis ${ }^{a}$

\begin{tabular}{|c|c|c|c|c|c|}
\hline Group & $\begin{array}{c}\text { Overall } \\
\mathrm{N}=8,710\end{array}$ & $\begin{array}{c}\text { Adalimumab } \\
\mathbf{n}=4,298\end{array}$ & $\begin{array}{c}\text { Etanercept } \\
\mathrm{n}=2,795\end{array}$ & $\begin{array}{c}\text { Infliximab } \\
\mathrm{n}=161\end{array}$ & $\begin{array}{c}\text { Ustekinumab } \\
\mathrm{n}=1,465\end{array}$ \\
\hline Patients, n (\%) & $8,710(100.0)$ & $4,289 \quad(49.2)$ & $2,795 \quad(32.1)$ & $161 \quad(1.8)$ & $1,465 \quad(16.8)$ \\
\hline Nonswitchers & $5,000 \quad(57.4)$ & $2,436 \quad(56.8)$ & $1,458 \quad(52.2)$ & $100 \quad(62.1)$ & $1,006 \quad(68.7)$ \\
\hline Switchers & $1,001 \quad(11.5)$ & $543 \quad(12.7)$ & $359 \quad(12.8)$ & $25 \quad(15.5)$ & $74 \quad(5.1)$ \\
\hline Discontinuers & $2,709 \quad(31.1)$ & $1,310 \quad(30.5)$ & $978 \quad(35.0)$ & $36 \quad(22.4)$ & $385 \quad(26.3)$ \\
\hline
\end{tabular}

aPercentages for treatment pattern subgroups were calculated from the total number of patients who initiated each therapy.

\section{Patient Demographics, Clinical Characteristics, and Treatment Patterns}

Of the 8,710 patients with psoriasis included in the study, 5,000 patients (57.4\%) were categorized as nonswitchers, 1,001 $(11.5 \%)$ as switchers, and 2,709 (31.1\%) as discontinuers. Of the 2,709 discontinuers, 1,870 patients (69.0\%) were considered pure discontinuers who did not initiate the same or different therapy during the 1-year follow-up period; 552 patients (20.4\%) reinitiated the same biologic therapy after the permissible gap cutoff during the 1-year follow-up period; and 287 patients $(10.6 \%)$ initiated a new biologic therapy following a gap in treatment of $\geq 3$ months, with a mean ( \pm standard deviation [SD]) time to initiation of 167.27 ( \pm 59.13 ) days (Appendix B, available in online article).

Patient demographics were mostly similar across treatment groups; overall, the mean $( \pm S D)$ age was $47.0( \pm 13.2)$ years, $52.4 \%$ were male, and most were from the South region of the United States (44.8\%; Table 2). Overall, the most prevalent comorbidities were hypertension (30.9\%), hyperlipidemia (29.3\%), and psoriatic arthritis (25.4\%). Nearly all patients were biologic naive (95.4\%). The most common nonbiologic therapies used during the baseline period were methotrexate sodium (25.0\%) and acitretin (5.0\%).

\section{Baseline All-Cause Health Care Resource Utilization and Costs}

Across all treatment groups, the mean $( \pm S D)$ number of patient visits per year was $0.09( \pm 0.35)$ for hospitalizations, $0.32( \pm 0.89)$ for ED visits, and $21.63( \pm 19.43)$ for outpatient visits (Table 2). Discontinuers had a significantly higher mean $( \pm$ SD) number of hospitalizations per patient per year than nonswitchers $(0.11[ \pm 0.37]$ vs. $0.08[ \pm 0.35] ; P<0.001)$. Both switchers and discontinuers had a significantly higher mean $( \pm S D)$ number of ED visits per patient per year compared with nonswitchers $(0.33[ \pm 0.91]$ and $0.40[ \pm 1.00]$ vs. $0.27[ \pm 0.81]$; $P=0.001$ and $P<0.001$, respectively). Switchers also had a significantly higher mean $( \pm S D)$ number of outpatient visits per patient per year compared with nonswitchers $(24.16[ \pm 19.70]$ vs. $21.62[ \pm 20.02] ; P<0.0001)$.

At baseline, the overall mean $( \pm S D)$ total all-cause health care cost across all treatment pattern groups was $\$ 11,852$
$( \pm \$ 20,277)$, and medical and prescription drug costs were significantly different between groups (Table 2). Switchers had significantly higher mean $( \pm S D)$ all-cause total health care costs than nonswitchers $(\$ 13,079[ \pm \$ 17,955]$ vs. $\$ 11,680$ $[ \pm \$ 19,737] ; P<0.001)$ and significantly higher medical $(\$ 8,283$ $[ \pm \$ 15,653]$ vs. $\$ 7,662[ \pm \$ 17,581] ; P<0.001)$ and prescription $\operatorname{drug}(\$ 4,795[ \pm \$ 6,849]$ vs. $\$ 4,018[ \pm \$ 7,242] ; P<0.001)$ costs. Compared with nonswitchers, discontinuers had significantly lower mean $( \pm S D)$ prescription drug costs $(\$ 3,515[ \pm \$ 6,053]$ vs. $\$ 4,018[ \pm \$ 7,242] ; P<0.001)$ and higher inpatient $(\$ 2,130$ $[ \pm \$ 13,613]$ vs. $\$ 1,745[ \pm \$ 11,018] ; P<0.001)$ and $\mathrm{ED}(\$ 683$ $[ \pm \$ 2,398]$ vs. $\$ 420[ \pm \$ 1,735] ; P<0.001)$ costs.

\section{Unadjusted All-Cause Health Care Resource Utilization and Costs During the 1-Year Follow-up Period}

In the 1-year follow-up period, discontinuers and switchers had higher all-cause health care utilization than nonswitchers (Table 3). Switchers had a significantly higher unadjusted mean $( \pm S D)$ number of $\mathrm{ED}(0.33[ \pm 0.91]$ vs. $0.27[ \pm 0.88]$; $P=0.003)$ and outpatient $(23.47[ \pm 17.54]$ vs. $19.42[ \pm 16.70]$; $P<0.001)$ visits per patient per year compared with nonswitchers. Discontinuers had a significantly higher unadjusted mean $( \pm$ SD) number of ED $(0.46[ \pm 1.06]$ vs. $0.27[ \pm 0.88] ; P<0.001)$, inpatient $(0.13[ \pm 0.49]$ vs. $0.06[ \pm 0.34] ; P<0.001)$, and outpatient $(20.46[ \pm 19.82]$ vs. $19.42[ \pm 16.70] ; P=0.015)$ visits per patient per year compared with nonswitchers.

In the 1-year follow-up period, switchers had a higher all-cause total health care cost compared with nonswitchers, while discontinuers had a lower all-cause total health care cost (Table 3). Switchers had a higher unadjusted mean $( \pm$ SD) total all-cause health care cost compared with nonswitchers $(\$ 60,734[ \pm \$ 27,523]$ vs. $\$ 51,133[ \pm \$ 25,483] ; P<0.001)$, which was contributed to by both increased prescription $(\$ 49,943$ $[ \pm \$ 20,650]$ vs. $\$ 42,315[ \pm \$ 19,036] ; P<0.001)$ and medical $(\$ 10,791[ \pm \$ 22,178]$ vs. $\$ 8,819[ \pm \$ 21,072] ; P<0.001)$ costs. The unadjusted mean total all-cause health care cost for discontinuers ( $\$ 33,828[ \pm \$ 41,281] ; P<0.001$ vs. nonswitchers) was much lower than that for the other treatment pattern groups due to reduced prescription costs $(\$ 21,978[ \pm \$ 16,946]$; $P<0.001$ vs. nonswitchers). 
Health Care Utilization and Cost Associated with Biologic Treatment Patterns Among

Patients with Moderate to Severe Psoriasis: Analyses from a Large U.S. Claims Database

TABLE 2 Baseline Patient Demographics and Clinical and Treatment Characteristics ${ }^{a}$

\begin{tabular}{|c|c|c|c|c|c|c|c|c|}
\hline \multirow{2}{*}{$\begin{array}{l}\text { Characteristic } \\
\text { Age, mean }( \pm S D) \text {, years }\end{array}$} & \multicolumn{2}{|c|}{$\begin{array}{c}\text { Overall } \\
\mathrm{N}=8,710\end{array}$} & \multicolumn{2}{|c|}{$\begin{array}{c}\text { Nonswitchers } \\
n=5,000\end{array}$} & \multicolumn{2}{|c|}{$\begin{array}{c}\text { Switchers } \\
n=1,001\end{array}$} & \multicolumn{2}{|c|}{$\begin{array}{c}\text { Discontinuers } \\
\mathbf{n}=2,709\end{array}$} \\
\hline & 47.0 & $( \pm 13.2)$ & 47.4 & $( \pm 12.9)$ & 47.8 & $( \pm 12.6)$ & 46.2 & $( \pm 13.9)^{\mathrm{b}}$ \\
\hline Male, n (\%) & 4,563 & $(52.4)$ & 2,823 & $(56.5)$ & 456 & $(46.6)^{b}$ & 1,284 & $(47.4)^{\mathrm{b}}$ \\
\hline Employment status (active full time), n (\%) & 5,850 & $(67.2)$ & 3,380 & $(67.6)$ & 686 & $(69.5)$ & 1,784 & $(66.9)^{b}$ \\
\hline \multicolumn{9}{|l|}{ Insurance plan type, n (\%) } \\
\hline Fee-for-service & 7,409 & $(85.1)$ & 4,259 & $(85.2)$ & 867 & $(86.6)$ & 2,283 & $(84.3)$ \\
\hline HMO and POS capitation & 1,185 & $(13.6)$ & 678 & (13.6) & 119 & (11.9) & 388 & (14.3) \\
\hline Unknown & 116 & $(1.3)$ & 63 & (1.3) & 15 & $(1.5)$ & 38 & (1.4) \\
\hline \multicolumn{9}{|l|}{ U.S. region, n (\%) } \\
\hline South & 3,818 & $(44.8)$ & 2,108 & $(42.2)$ & 445 & $(44.5)$ & 1,265 & $(46.7)^{c}$ \\
\hline North central & 2,002 & $(23.0)$ & 1,168 & $(23.4)$ & 241 & $(24.1)$ & 593 & $(21.9)^{c}$ \\
\hline Northeast & 1,343 & $(15.4)$ & 816 & $(16.3)$ & 156 & (15.6) & 371 & $(13.7)^{c}$ \\
\hline West & 1,435 & $(16.5)$ & 840 & (16.8) & 149 & $(14.9)$ & 446 & $(16.5)^{\mathrm{c}}$ \\
\hline Unknown & 112 & $(1.3)$ & 68 & $(1.4)$ & 10 & $(1.0)$ & 34 & $(1.3)^{c}$ \\
\hline CCI score, mean $( \pm \mathrm{SD})$ & 0.51 & $( \pm 1.07)$ & 0.48 & $( \pm 1.02)$ & 0.54 & $( \pm 1.05)$ & 0.55 & $( \pm 1.16)^{b}$ \\
\hline \multicolumn{9}{|l|}{ Comorbidities, n (\%) } \\
\hline Hypertension & 2,686 & $(30.9)$ & 1,529 & $(30.6)$ & 342 & $(34.2)^{\mathrm{b}}$ & 815 & $(30.1)$ \\
\hline Hyperlipidemia & 2,553 & $(29.3)$ & 1,497 & $(30.0)$ & 286 & $(28.6)$ & 770 & $(28.4)$ \\
\hline Psoriatic arthritis & 2,215 & $(25.4)$ & 1,298 & $(26.0)$ & 297 & $(30.0)^{b}$ & 620 & $(22.9)^{\mathrm{b}}$ \\
\hline Diabetes & 1,209 & (13.9) & 673 & (13.5) & 149 & $(14.9)$ & 387 & $(14.3)$ \\
\hline Depression & 890 & $(10.2)$ & 476 & $(9.5)$ & 111 & $(11.1)$ & 303 & $(11.2)^{\mathrm{b}}$ \\
\hline Anxiety & 712 & $(8.2)$ & 370 & (7.4) & 88 & $(8.8)$ & 254 & $(9.4)^{\mathrm{b}}$ \\
\hline Obesity & 722 & $(8.2)$ & 400 & $(8.0)$ & 89 & $(9.0)$ & 233 & $(8.6)$ \\
\hline \multicolumn{9}{|l|}{ Treatment characteristics, n (\%) } \\
\hline Biologic naive & 8,307 & $(95.4)$ & 4,752 & $(95.0)$ & 939 & $(93.8)$ & 2,616 & $(96.6)$ \\
\hline Biologic experienced & 403 & $(4.6)$ & 248 & $(5.0)$ & 62 & $(6.2)$ & 93 & $(3.4)$ \\
\hline \multicolumn{9}{|l|}{ Nonbiologic use, n (\%) } \\
\hline Methotrexate sodium & 2,177 & $(25.0)$ & 1,308 & $(26.2)$ & 284 & $(28.4)$ & 585 & $(21.6)^{\mathrm{b}}$ \\
\hline Acitretin & 436 & $(5.0)$ & 236 & $(4.7)$ & 68 & $(6.8)^{\mathrm{b}}$ & 132 & $(4.9)$ \\
\hline Cyclosporine & 245 & (2.8) & 133 & $(2.7)$ & 40 & $(4.0)^{b}$ & 72 & $(2.7)$ \\
\hline Apremilast & 51 & $(0.6)$ & 26 & $(0.5)$ & 11 & $(1.1)^{\mathrm{b}}$ & 14 & $(0.5)$ \\
\hline \multicolumn{9}{|c|}{ Total all-cause health care resource utilization per patient per year, mean $( \pm$ SD $)$} \\
\hline Hospitalizations & 0.09 & $( \pm 0.35)$ & 0.08 & $( \pm 0.35)$ & 0.07 & $( \pm 0.30)$ & 0.11 & $( \pm 0.37)^{\mathrm{b}}$ \\
\hline ED visits & 0.32 & $( \pm 0.89)$ & 0.27 & $( \pm 0.81)$ & 0.33 & $( \pm 0.91)^{\mathrm{b}}$ & 0.40 & $( \pm 1.00)^{\mathrm{b}}$ \\
\hline Outpatient visits & 21.63 & $( \pm 19.43)$ & 21.62 & $( \pm 20.02)$ & 24.16 & $( \pm 19.70)^{\mathrm{b}}$ & 20.71 & $( \pm 18.12)$ \\
\hline Total all-cause health care costs $(\$)$, mean $( \pm S D)^{d}$ & 11,852 & $( \pm 20,277)$ & 11,680 & $( \pm 19,737)$ & 13,079 & $( \pm 17,955)^{\mathrm{b}}$ & 11,717 & $( \pm 21,988)$ \\
\hline Prescription drug costs & 3,951 & $( \pm 6,858)$ & 4,018 & $( \pm 7,242)$ & 4,795 & $( \pm 6,849)^{\mathrm{b}}$ & 3,515 & $( \pm 6,053)^{\mathrm{b}}$ \\
\hline Medical costs ${ }^{\mathrm{e}}$ & 7,901 & $( \pm 18,262)$ & 7,662 & $( \pm 17,581)$ & 8,283 & $( \pm 15,653)^{\mathrm{b}}$ & 8,202 & $( \pm 20,281)$ \\
\hline ED costs & 524 & $( \pm 2,043)$ & 420 & $( \pm 1,735)$ & 611 & $( \pm 2,370)$ & 683 & $( \pm 2,398)^{b}$ \\
\hline Inpatient costs & 1,843 & $( \pm 11,825)$ & 1,745 & $( \pm 11,018)$ & 1,556 & $( \pm 10,428)$ & 2,130 & $( \pm 13,613)^{b}$ \\
\hline Outpatient costs & 5,534 & $( \pm 10,936)$ & 5,497 & $( \pm 11,253)$ & 6,115 & $( \pm 9,142)^{b}$ & 5,389 & $( \pm 10,946)$ \\
\hline \multicolumn{9}{|c|}{ 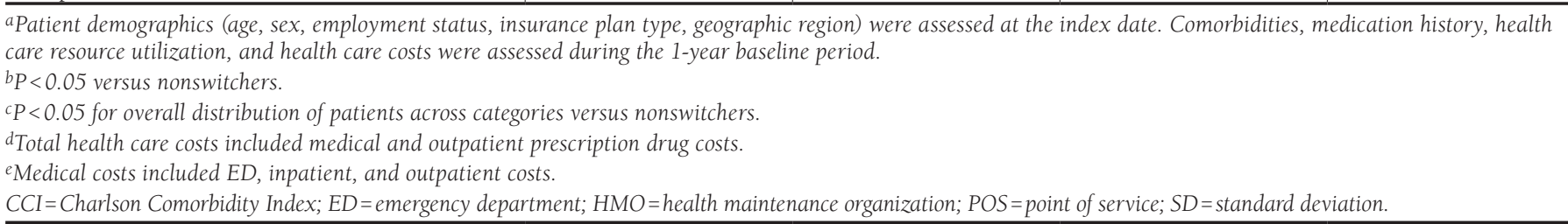 } \\
\hline
\end{tabular}

\section{Adjusted All-Cause Health Care Resource Utilization and Costs During the 1-Year Follow-up Period}

Multivariable modeling adjusting for covariates (age, sex, geographic region, insurance plan type, index drug, index year, baseline CCI, baseline resource utilization, baseline total health care costs, and baseline nonbiologic medications) further revealed higher health care utilization for switchers and discontinuers compared with nonswitchers. Compared with nonswitchers, ED and inpatient visits, respectively, were more frequent among switchers (adjusted incidence rate ratio 
TABLE 3 Unadjusted Health Care Resource Utilization and Costs During 1-Year Follow-up

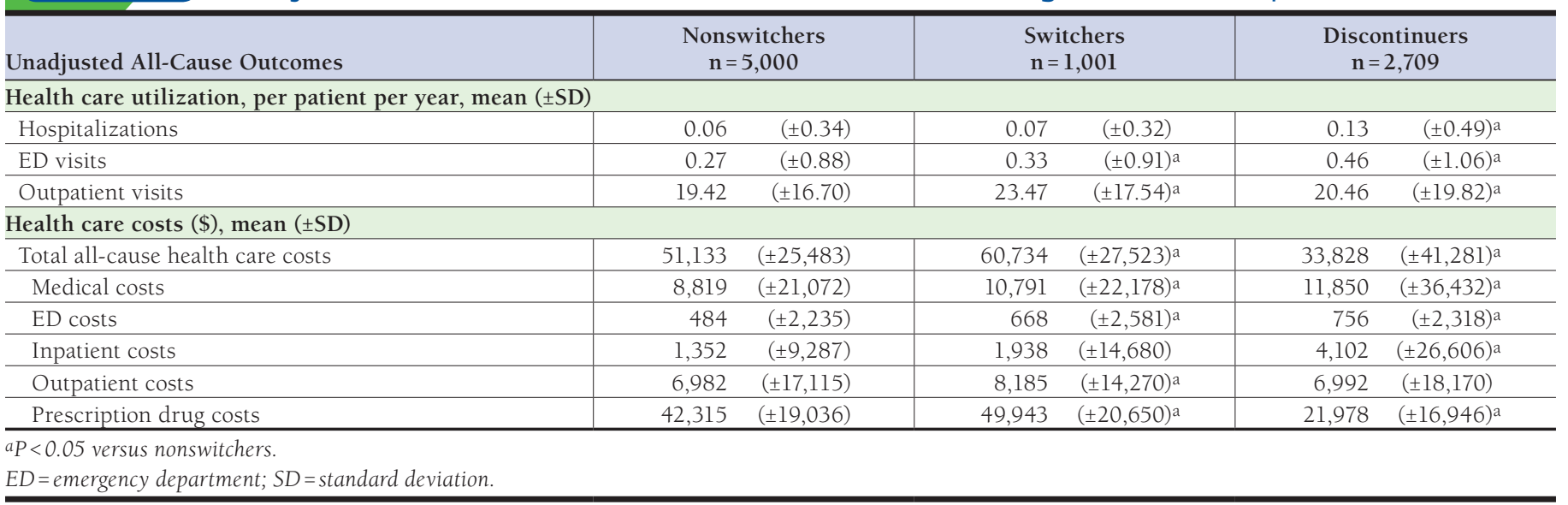

[IRR] [95\% CI]: 1.10 [0.93-1.30] and 1.13 [0.84-1.53]) and discontinuers (1.50 [1.34-1.68] and 2.05 [1.70-2.48]; Table 4). Switchers also had an increased IRR of outpatient visits versus nonswitchers (adjusted IRR [95\% CI]: 1.18 [1.16-1.21]).

Multivariable modeling adjusting for the same baseline covariates as above revealed higher health care costs for switchers compared with nonswitchers (Table 4). Compared with nonswitchers, switchers had a higher adjusted total all-cause health care cost (mean difference [95\% CI]: \$10,120 [\$8,235$\$ 12,033]$ ), which was driven by both increased prescription drug costs $(\$ 8,988[\$ 7,535-\$ 10,610])$ and medical costs $(\$ 2,746[\$ 1,090-\$ 4,677])$. The total all-cause health care cost for discontinuers (mean difference vs. nonswitchers [95\% CI]: $-\$ 18,611[-\$ 20,254,-\$ 17,025])$ was much lower than that for the other treatment pattern groups due to reduced prescription costs $(-\$ 20,486[-\$ 21,319,-\$ 19,636])$; however, discontinuers had the highest medical cost (mean difference vs. nonswitchers [95\% CI]: \$3,729 [\$1,970-\$5,527]).

\section{Discussion}

This study aimed to evaluate the health care resource utilization and costs of switching, discontinuing, or remaining on initial biologic therapy among patients with moderate to severe psoriasis during a 1-year follow-up period. In this updated retrospective analysis of a U.S. administrative claims database, patients with psoriasis who switched or discontinued biologics endured a greater economic burden than patients who remained on their index biologic. Overall, 57.4\% of patients remained on their index biologic, $11.5 \%$ switched their biologic, and 31.1\% discontinued their biologic therapy within the 1-year follow-up period. These switching patterns are similar to what was observed in a previous study using the Truven Health Analytics MarketScan CCAE and MDCR databases, suggesting that these results are reproducible in an updated analysis of a larger study population, with a study period that better reflects current biologic treatment patterns and use in clinical practice. ${ }^{36}$ At baseline, switchers and discontinuers had significantly higher health care resource utilization and medical costs compared with nonswitchers. Switchers had the highest all-cause total health care costs, followed by nonswitchers and discontinuers. The high all-cause total health care costs for switchers, compared with nonswitchers, were contributed to by both higher medical and prescription costs. Discontinuers had lower all-cause total health care costs due to lower prescription costs than nonswitchers. The difference in baseline health care utilization and costs required further analyses to directly compare these 3 treatment pattern groups.

Adjusted all-cause health care utilization and cost subcategories reported during the 1-year follow-up period demonstrated similar trends regarding treatment pattern groups. In particular, patients who switched or discontinued biologics had higher health care utilization and higher medical costs than those who remained on their index biologics. Similarly, patients who switched biologics had the highest total health care costs (1.2-fold higher vs. nonswitchers), driven by an increase in both prescription (1.2-fold higher vs. nonswitchers) and medical (1.3-fold higher vs. nonswitchers) costs. The mean total health care cost for discontinuers was much lower than that for the other treatment pattern groups (1.6fold lower vs. nonswitchers) due to lower prescription costs (1.9-fold lower vs. nonswitchers) from early discontinuation of therapy. However, discontinuers had the highest mean medical cost (1.4-fold higher vs. nonswitchers), indicating that these patients may not have had stable disease states. Of the $287(10.6 \%)$ discontinuers who initiated a new therapy with a mean $( \pm S D)$ time to initiation of $167.27( \pm 59.13)$ days, 100 (34.8\%) of these new initiators had discontinuation gaps of $\geq 6$ months (Appendix B). Because these patients may not be true 
TABLE 4 Adjusted Health Care Resource Utilization and Costs During 1-Year Follow-up Among the 3 Treatment Pattern Groups ${ }^{\mathrm{a}}$

\begin{tabular}{|c|c|c|c|c|}
\hline Adjusted All-Cause Outcomes & \multicolumn{2}{|c|}{ Switchers vs. Nonswitchers } & \multicolumn{2}{|c|}{ Discontinuers vs. Nonswitchers } \\
\hline \multicolumn{5}{|c|}{ Health care resource utilization (count outcomes), IRR (95\% CI) } \\
\hline Hospitalizations $^{b}$ & 1.13 & $(0.84-1.53)$ & 2.05 & $(1.70-2.48)$ \\
\hline ED visits ${ }^{b}$ & 1.10 & $(0.93-1.30)$ & 1.50 & $(1.34-1.68)$ \\
\hline Outpatient visits ${ }^{\mathrm{c}}$ & 1.18 & $(1.16-1.21)$ & 1.01 & $(1.00-1.03)$ \\
\hline \multicolumn{5}{|c|}{ Health care costs $(\$)$, mean difference $(95 \% \mathrm{CI})^{\mathrm{d}}$} \\
\hline Total all-cause health care costs & 10,120 & $(8,235-12,033)$ & $-18,611$ & $(-\$ 20,254$ to $-\$ 17,025)$ \\
\hline Medical costs & 2,746 & $(1,090-4,677)$ & 3,729 & $(1,970-5,527)$ \\
\hline ED costs & 170 & $(15-341)$ & 298 & $(198-409)$ \\
\hline Inpatient costs & 482 & $(29-1,470)$ & 2,578 & $(2,445-2,973)$ \\
\hline Outpatient costs & 2,028 & $(1,470-3,067)$ & 525 & $(29-1,394)$ \\
\hline Prescription drug costs & 8,988 & $(7,535-10,610)$ & $-20,486$ & $(-\$ 21,319$ to $-\$ 19,636)$ \\
\hline \multicolumn{5}{|c|}{$\begin{array}{l}\text { aCovariates included age, sex, geographic region, insurance plan type, index drug, index year, baseline Charlson Comorbidity Index, baseline health care resource } \\
\text { utilization, baseline total health care costs, and baseline nonbiologic medications. } \\
{ }^{b} \text { Hospitalizations and ED visit IRRs were derived from a negative binomial model. } \\
\text { cOutpatient visit IRRs were derived from a Poisson model. } \\
\text { dHealth care costs were modeled using generalized linear regression with a log link and gamma distribution or 2-part models. For 2-part models, logistic regression was } \\
\text { used to model probabilities of positive costs followed by gamma regression to model costs among patients with positive costs. } \\
C I=\text { confidence interval; ED = emergency department; IRR=incidence rate ratio. }\end{array}$} \\
\hline
\end{tabular}

discontinuers, including patients in the discontinuer group who initiated new therapies after the permissible treatment gap introduces a potential bias in the results. Because discontinuers had lower health care costs, including patients who initiated new therapies would inaccurately increase the total health care costs driven by increased prescription drug costs. However, the substantial length of the mean time to initiation and relatively large proportion of patients who did not initiate a new therapy until $\geq 6$ months after discontinuation would not result in a notable change in the adjusted model analyses. This suggests that remaining on a biologic is less of an economic burden than is switching or discontinuing biologic treatments due to incurring less health care resource utilization through a lower incidence rate of hospitalization, ED, and outpatient visits and lower prescription and medical costs. These findings are consistent with those of another retrospective study in a large U.S. health plan database, which demonstrated that prevalence of prescription fills and inpatient and ED visits, and not biologic use or costs of biologic therapies, were the main drivers of cost among patients with psoriasis. ${ }^{44}$

A more robust sensitivity analysis that stratified patients based on prior biologic use (biologic naive vs. biologic experienced) demonstrated a similar trend: patients in both cohorts who switched or discontinued biologics had higher health care utilization and medical costs. This finding suggests that prior biologic use did not affect the analyses and further implicates that higher health care utilization and costs are associated with switching or discontinuing biologics.

Although the current study did not inform on the reasons for switching biologic therapies, common reasons for switching between TNFis have been documented in real-world settings and include inadequate response or failure to maintain response to treatment, adverse events, and/or lack of insurance. ${ }^{45}$ This current study reveals higher all-cause health care utilization and higher all-cause health care costs in patients who switch biologics and provides insight into the economic consequences associated with biologic switching. Few studies in the United States have reported on health care utilization and costs of biologic switching or discontinuation among patients with psoriasis; therefore, this study provides valuable insight into the financial implications of switching treatment that may inform formulary decision making for payers. From a policy perspective, administrators will need to weigh the cost of forcing patients and physicians to switch therapies versus the savings with remaining on current therapy, potentially leading to changes in designs for formulary tiering. Furthermore, these findings provide essential information to clinicians for proper treatment and management by implicating tighter management of patients with psoriasis on biologics as a means to alleviate both clinical and economic burden.

\section{Limitations}

Despite having several strengths, this study has a few limitations that are mainly related to the nature of claims data used for analysis. The current findings may not be generalizable to the general population because the data used were limited to those patients who had commercial and Medicare supplemental insurance, and this analysis may have underestimated the costs for patients who received supplemental health 
care or who did not have insurance coverage included in the claims database. It could not be conclusively determined from the administrative claims data whether the biologics investigated in this study were used specifically for the treatment of psoriasis. Patients with conditions that required a prescription of similar classes of biologics (e.g., rheumatoid arthritis, psoriatic arthritis, ankylosing spondylitis, ulcerative colitis) were excluded by the relevant ICD-9-CM codes. However, the possibility of biologic use for disorders that were not included in the exclusion criteria or other autoimmune disorders that were not documented in the claims database could not be ruled out.

Because the biologic switch patterns and resulting effect on health care utilization and costs were only covered during a 1-year follow-up, this study could not provide insight into the long-term economic implications associated with biologic treatment and switching in patients with psoriasis. Other variables affecting cost, such as adverse effects with prolonged use of these drugs and disease progression, could not be captured by this study.

The analysis did not examine predictors of, reasons for, or clinical consequences of switching or discontinuing biologic treatment; therefore, patients could have discontinued treatment for reasons unrelated to lack of efficacy, such as de-escalation to nonbiologic therapies. Also, the analyses were not adjusted by a clinical metric, such as the Psoriasis Area Severity Index, and any indirect costs, such as work productivity, could not be ascertained due to lack of information in the claims database.

Additional long-term analyses of real-world data will be required to corroborate these findings and to assess clinical and economic outcomes associated with switching from or discontinuing newer biologic therapies, such as the IL-17A inhibitors secukinumab and ixekizumab, the IL-17RA inhibitor brodalumab, and the IL-23 inhibitor guselkumab.

\section{Conclusions}

This updated analysis of U.S. administrative claims data suggests that patients with psoriasis who switch or discontinue biologics within the first year of initiating their biologic have higher health care utilization and higher medical costs than patients remaining on their index biologic. These findings better reflect current treatment patterns and use in clinical practice and highlight the clinical and economic effects of discontinuing or switching biologic therapies in patients with psoriasis, which may inform treatment and/or formulary decision making. Furthermore, these results suggest a need to identify treatments with sustained safety and efficacy to alleviate the clinical and economic burden of discontinuing or switching biologic therapies.

\section{Authors}

STEVEN R. FELDMAN, MD, PhD, Department of Dermatology, Wake Forest Baptist Medical Center, Winston-Salem, North Carolina. HAIJUN TIAN, PhD, Center of Excellence for Real World Evidence, and REBECCA GERMINO, PhD, Health Economics \& Outcomes Research, Novartis Pharmaceuticals Corporation, East Hanover, New Jersey. XINYUE WANG, MS, KMK Consulting, Morristown, New Jersey.

AUTHOR CORRESPONDENCE: Steven R. Feldman, MD, PhD, Wake Forest School of Medicine, Department of Dermatology, 4618 Country Club Rd., Winston-Salem, NC 27104. Tel.: 336.716.7740; E-mail:sfeldman@wakehealth.edu.

\section{DISCLOSURES}

This study was sponsored by Novartis Pharmaceuticals Corporation. Feldman has received consulting, speaking, and/or research support from Novartis, AbbVie, Celgene, Sun Pharma, Janssen, Lilly, and Ortho. Tian and Germino are employees of Novartis. Wang was an employee of KMK Consulting and worked as a consultant for Novartis at the time of this study.

Portions of this work were presented at the 2017 Fall Clinical Dermatology Conference; October 12-15, 2017; Las Vegas, NV; the 2017 Las Vegas Dermatology Seminar; November 2-4, 2017; Las Vegas, NV; and the 2018 American Academy of Dermatology Annual Meeting; February 16-20, 2018; San Diego, CA.

\section{ACKNOWLEDGMENTS}

Eric Deutsch, PhD, and Meaghan Paganelli, PhD, of Health Interactions, provided third-party writing assistance for this manuscript, which was funded by Novartis Pharmaceuticals Corporation.

\section{REFERENCES}

1. Menter A, Gottlieb A, Feldman SR, et al. Guidelines of care for the management of psoriasis and psoriatic arthritis: Section 1. Overview of psoriasis and guidelines of care for the treatment of psoriasis with biologics. J Am Acad Dermatol. 2008;58(5):826-50.

2. Myers WA, Gottlieb AB, Mease P. Psoriasis and psoriatic arthritis: clinical features and disease mechanisms. Clin Dermatol. 2006;24(5):438-47.

3. Rachakonda TD, Schupp CW, Armstrong AW. Psoriasis prevalence among adults in the United States. J Am Acad Dermatol. 2014;70(3):512-16.

4. Langley RG, Krueger GG, Griffiths CE. Psoriasis: epidemiology, clinical features, and quality of life. Ann Rheum Dis. 2005;64(Suppl 2):iil8-23; discussion ii24-5.

5. Lebwohl MG, Kavanaugh A, Armstrong AW, Van Voorhees AS. U.S. perspectives in the management of psoriasis and psoriatic arthritis: patient and physician results from the population-based Multinational Assessment of Psoriasis and Psoriatic Arthritis (MAPP) survey. Am J Clin Dermatol. 2016;17(1):87-97.

6. Brezinski EA, Dhillon JS, Armstrong AW. Economic burden of psoriasis in the United States: a systematic review. JAMA Dermatol. 2015;151(6):651-58.

7. Bickers DR, Lim HW, Margolis D, et al. The burden of skin diseases: 2004 a joint project of the American Academy of Dermatology Association and the Society for Investigative Dermatology. J Am Acad Dermatol. 2006;55(3):490-500.

8. Jenner N, Campbell J, Plunkett A, Marks R. Cost of psoriasis: a study on the morbidity and financial effects of having psoriasis in Australia. Australas J Dermatol. 2002;43(4):255-61. 
9. Schoffski O, Augustin M, Prinz J, et al. Costs and quality of life in patients with moderate to severe plaque-type psoriasis in Germany: a multicenter study. J Dtsch Dermatol Ges. 2007;5(3):209-18

10. Gordon KB, Langley RG, Leonardi C, et al. Clinical response to adalimumab treatment in patients with moderate to severe psoriasis: double-blind, randomized controlled trial and open-label extension study. J Am Acad Dermatol. 2006;55(4):598-606.

11. Elewski BE, Okun MM, Papp K, et al. Adalimumab for nail psoriasis: efficacy and safety from the first 26 weeks of a phase 3, randomized, placebocontrolled trial. J Am Acad Dermatol. 2018;78(1):90-9.el.

12. Leonardi CL, Powers JL, Matheson RT, et al. Etanercept as monotherapy in patients with psoriasis. N Engl J Med. 2003;349(21):2014-22.

13. Papp K, Reich K, Leonardi CL, et al. Apremilast, an oral phosphodiesterase 4 (PDE4) inhibitor, in patients with moderate to severe plaque psoriasis: results of a phase III, randomized, controlled trial (Efficacy and Safety Trial Evaluating the Effects of Apremilast in Psoriasis [ESTEEM] 1). J Am Acad Dermatol. 2015;73(1):37-49.

14. Papp KA, Tyring S, Lahfa M, et al. A global phase III randomized controlled trial of etanercept in psoriasis: safety, efficacy, and effect of dose reduction. Br J Dermatol. 2005;152(6):1304-12.

15. Paller AS, Siegfried EC, Langley RG, et al. Etanercept treatment for children and adolescents with plaque psoriasis. N Engl J Med. 2008;358(3):241-51.

16. Reich K, Nestle FO, Papp K, et al. Infliximab induction and maintenance therapy for moderate-to-severe psoriasis: a phase III, multicentre, doubleblind trial. Lancet. 2005;366(9494):1367-74.

17. Menter A, Feldman SR, Weinstein GD, et al. A randomized comparison of continuous vs. intermittent infliximab maintenance regimens over 1 year in the treatment of moderate-to-severe plaque psoriasis. J Am Acad Dermatol. 2007;56(1):31.el-31.15.

18. Gottlieb AB, Evans R, Li S, et al. Infliximab induction therapy for patients with severe plaque-type psoriasis: a randomized, double-blind, placebo-controlled trial. J Am Acad Dermatol. 2004;51(4):534-42.

19. Leonardi CL, Kimball AB, Papp KA, et al. Efficacy and safety of ustekinumab, a human interleukin-12/23 monoclonal antibody, in patients with psoriasis: 76-week results from a randomised, double-blind, placebocontrolled trial (PHOENIX 1). Lancet. 2008;371(9625):1665-74.

20. Papp KA, Langley RG, Lebwohl M, et al. Efficacy and safety of ustekinumab, a human interleukin-12/23 monoclonal antibody, in patients with psoriasis: 52-week results from a randomised, double-blind, placebocontrolled trial (PHOENIX 2). Lancet. 2008;371(9625):1675-84.

21. Landells I, Marano C, Hsu MC, et al. Ustekinumab in adolescent patients age 12 to 17 years with moderate-to-severe plaque psoriasis: results of the randomized phase 3 CADMUS study. J Am Acad Dermatol. 2015;73(4):594-603.

22. Blauvelt A, Papp KA, Griffiths CE, et al. Efficacy and safety of guselkumab, an anti-interleukin-23 monoclonal antibody, compared with adalimumab for the continuous treatment of patients with moderate to severe psoriasis: results from the phase III, double-blinded, placebo- and active comparatorcontrolled VOYAGE 1 trial. J Am Acad Dermatol. 2017;76(3):405-17.

23. Reich K, Armstrong AW, Foley P, et al. Efficacy and safety of guselkumab, an anti-interleukin-23 monoclonal antibody, compared with adalimumab for the treatment of patients with moderate to severe psoriasis with randomized withdrawal and retreatment: results from the phase III, doubleblind, placebo- and active comparator-controlled VOYAGE 2 trial. J Am Acad Dermatol. 2017;76(3):418-31.

24. Langley RG, Tsai TF, Flavin S, et al. Efficacy and safety of guselkumab in patients with psoriasis who have an inadequate response to ustekinumab: results of the randomized, double-blind, phase III NAVIGATE trial. Br J Dermatol. 2018;178(1):114-23.

25. Reich K, Papp KA, Blauvelt A, et al. Tildrakizumab versus placebo or etanercept for chronic plaque psoriasis (reSURFACE 1 and reSURFACE 2): results from two randomised controlled, phase 3 trials. Lancet. 2017;390(10091):276-88.

26. Langley RG, Elewski BE, Lebwohl M, et al. Secukinumab in plaque psoriasis_results of two phase 3 trials. N Engl J Med. 2014;371(4):326-38.
27. Blauvelt A, Prinz JC, Gottlieb AB, et al. Secukinumab administration by pre-filled syringe: efficacy, safety and usability results from a randomized controlled trial in psoriasis (FEATURE). Br J Dermatol. 2015;172(2):484-93.

28. Paul C, Lacour JP, Tedremets L, et al. Efficacy, safety and usability of secukinumab administration by autoinjector/pen in psoriasis: a randomized, controlled trial (JUNCTURE). J Eur Acad Dermatol Venereol. 2015;29(6):1082-90.

29. Gordon KB, Colombel JF, Hardin DS. Phase 3 trials of ixekizumab in moderate-to-severe plaque psoriasis. N Engl J Med. 2016;375(21):2102.

30. Griffiths CE, Reich K, Lebwohl M, et al. Comparison of ixekizumab with etanercept or placebo in moderate-to-severe psoriasis (UNCOVER-2 and UNCOVER-3): results from two phase 3 randomised trials. Lancet. 2015;386(9993):541-51.

31. Papp KA, Reich K, Paul C, et al. A prospective phase III, randomized, double-blind, placebo-controlled study of brodalumab in patients with moderate-to-severe plaque psoriasis. Br J Dermatol. 2016;175(2):273-86.

32. Lebwohl M, Strober B, Menter A, et al. Phase 3 studies comparing brodalumab with ustekinumab in psoriasis. N Engl J Med. 2015;373(14):1318-28.

33. Langley RG. Effective and sustainable biologic treatment of psoriasis: what can we learn from new clinical data? J Eur Acad Dermatol Venereol. 2012;26(Suppl 2):21-29.

34. Saccomani C, Penz S, Guerre-Schmidt R, et al. Experience with biologics for psoriasis in daily practice: rotational therapy is required. J Dermatolog Treat. 2011;22(3):151-52.

35. Lecluse LL, de Groot M, Bos JD, Spuls PI. Experience with biologics for psoriasis in daily practice: switching is worth a try. Br J Dermatol. 2009;161(4):948-51.

36. Feldman SR, Zhao Y, Navaratnam P, Friedman HS, Lu J, Tran MH. Patterns of medication utilization and costs associated with the use of etanercept, adalimumab, and ustekinumab in the management of moderate-tosevere psoriasis. J Manag Care Spec Pharm. 2015;21(3):201-09. Available at https://www.jmcp.org/doi/10.18553/jmcp.2015.21.3.201.

37. Bonafede M, Johnson BH, Fox KM, Watson C, Gandra SR. Treatment patterns with etanercept and adalimumab for psoriatic diseases in a realworld setting. J Dermatolog Treat. 2013;24(5):369-73.

38. Chastek B, White J, Van Voorhis D, Tang D, Stolshek BS. A retrospective cohort study comparing utilization and costs of biologic therapies and JAK inhibitor therapy across four common inflammatory indications in adult U.S. managed care patients. Adv Ther. 2016;33(4):626-42.

39. Bonafede M, Fox KM, Watson C, Princic N, Gandra SR. Treatment patterns in the first year after initiating tumor necrosis factor blockers in realworld settings. Adv Ther. 2012;29(8):664-74.

40. Armstrong AW, Koning JW, Rowse S, Tan H, Mamolo C, Kaur M. Initiation, switching, and cessation of psoriasis treatments among patients with moderate to severe psoriasis in the United States. Clin Drug Investig. 2017;37(5):493-501

41. Tian H, Gilloteau I, Mollon P, McDwyer P, Lotya J. Biologics switching patterns and associated costs in psoriasis patients in a large commercially insured population in the United States [abstract]. Value Health. 2016;19(3):A125.

42. Mallya U, Qureshi A, Lahoz R. The economic burden of switching biologics in psoriasis: a real-world analysis in the U.S. population. J Am Acad Dermatol. 2014:70(5):AB191.

43. Charlson ME, Pompei P, Ales KL, MacKenzie CR. A new method of classifying prognostic comorbidity in longitudinal studies: development and validation. J Chronic Dis. 1987;40(5):373-83.

44. Armstrong AW, Zhao Y, Herrera V, et al. Drivers of healthcare costs among the costliest patients with psoriasis over three years in a United States health plan. J Drugs Dermatol. 2017;16(7):651-58.

45. Honda H, Umezawa Y, Kikuchi S, et al. Switching of biologics in psoriasis: reasons and results. J Dermatol. 2017;44(9):1015-19. 
Health Care Utilization and Cost Associated with Biologic Treatment Patterns Among

Patients with Moderate to Severe Psoriasis: Analyses from a Large U.S. Claims Database

\section{APPENDIX A Index Drug NDC Numbers and HCPCS Codes}

\begin{tabular}{|c|c|c|c|c|c|}
\hline Generic Name & NDC Number & HCPCS Code & Obsolete Date & Active & Strength \\
\hline Adalimumab & 00074-3799-02 & J0135 & & Yes & $40 \mathrm{mg} / 0.8 \mathrm{~mL}$ \\
\hline Adalimumab & 00074-3799-03 & J0135 & & Yes & $40 \mathrm{mg} / 0.8 \mathrm{~mL}$ \\
\hline Adalimumab & 00074-3799-06 & J0135 & & Yes & $40 \mathrm{mg} / 0.8 \mathrm{~mL}$ \\
\hline Adalimumab & 00074-4339-02 & J0135 & & Yes & $40 \mathrm{mg} / 0.8 \mathrm{~mL}$ \\
\hline Adalimumab & 00074-4339-06 & J0135 & & Yes & $20 \mathrm{mg} / 0.4 \mathrm{~mL}$ \\
\hline Adalimumab & 00074-4339-07 & J0135 & & Yes & $40 \mathrm{mg} / 0.8 \mathrm{~mL}$ \\
\hline Adalimumab & 00074-4339-71 & & & No & $10 \mathrm{mg} / 0.2 \mathrm{~mL}$ \\
\hline Adalimumab & $00074-6347-02$ & J0135 & & Yes & $20 \mathrm{mg} / 0.4 \mathrm{~mL}$ \\
\hline Adalimumab & 00074-9374-02 & J0135 & & Yes & $40 \mathrm{mg} / 0.8 \mathrm{~mL}$ \\
\hline Adalimumab & 54569-5524-00 & & 03/10/2005 & No & $40 \mathrm{mg} / 0.8 \mathrm{~mL}$ \\
\hline Adalimumab & $54868-4822-00$ & & $06 / 30 / 2011$ & No & $30 \mathrm{mg}$ \\
\hline Etanercept & $54868-4782-00$ & J1438 & $06 / 30 / 2012$ & No & $25 \mathrm{mg}(1 \mathrm{~mL})$ \\
\hline Etanercept & 54868-5444-00 & & & Yes & $50 \mathrm{mg} / \mathrm{mL}(0.98 \mathrm{~mL})$ \\
\hline Etanercept & $58406-0425-34$ & J1438 & & Yes & $25 \mathrm{mg}(1 \mathrm{~mL})$ \\
\hline Etanercept & 58406-0425-41 & & & Yes & $25 \mathrm{mg}(1 \mathrm{~mL})$ \\
\hline Etanercept & 58406-0435-01 & & & Yes & $50 \mathrm{mg} / \mathrm{mL}(0.98 \mathrm{~mL})$ \\
\hline Etanercept & 58406-0435-04 & J1438 & & Yes & $50 \mathrm{mg} / \mathrm{mL}(0.98 \mathrm{~mL})$ \\
\hline Etanercept & 58406-0445-01 & & & Yes & $50 \mathrm{mg} / \mathrm{mL}(0.98 \mathrm{~mL})$ \\
\hline Etanercept & 58406-0445-04 & J1438 & & Yes & $50 \mathrm{mg} / \mathrm{mL}(0.98 \mathrm{~mL})$ \\
\hline Etanercept & $58406-0455-01$ & & & Yes & $25 \mathrm{mg} / 0.5 \mathrm{~mL}(0.51 \mathrm{~mL})$ \\
\hline Etanercept & 58406-0455-04 & $\mathrm{J} 1438$ & & Yes & $25 \mathrm{mg} / 0.5 \mathrm{~mL}(0.51 \mathrm{~mL})$ \\
\hline Infliximab & 57894-0030-01 & $\mathrm{J} 1745$ & & Yes & $100 \mathrm{mg}$ \\
\hline Ustekinumab & 57894-0060-02 & $\mathrm{J} 3357$ & $10 / 14 / 2010$ & No & $45 \mathrm{mg} / 0.5 \mathrm{~mL}$ \\
\hline Ustekinumab & 57894-0060-03 & $\mathrm{J} 3357$ & & Yes & $45 \mathrm{mg} / 0.5 \mathrm{~mL}$ \\
\hline Ustekinumab & 57894-0061-03 & $\mathrm{J} 3357$ & & Yes & $90 \mathrm{mg} / \mathrm{mL}$ \\
\hline
\end{tabular}

\begin{tabular}{|c|c|c|c|}
\hline \multirow[t]{2}{*}{ APPENDIX B } & \multicolumn{3}{|c|}{$\begin{array}{l}\text { Time to Initiate New Therapy } \\
\text { Among Patients Who Discontinued } \\
\text { the Index Drug }\end{array}$} \\
\hline & & $\begin{array}{r}\text { New I } \\
\mathbf{n}\end{array}$ & $\begin{array}{l}\text { nitiators } \\
287\end{array}$ \\
\hline \multicolumn{2}{|c|}{ Time to initiate different therapy, mean $( \pm S D)$, days } & 167.3 & $( \pm 59.1)$ \\
\hline \multicolumn{4}{|c|}{ Number of patients at discontinuation gaps, $\mathbf{n}(\%)$} \\
\hline \multicolumn{2}{|l|}{ 3-4 months } & 75 & $(26.1)$ \\
\hline \multicolumn{2}{|l|}{$4-5$ months } & 63 & $(22.0)$ \\
\hline \multicolumn{2}{|l|}{ 5-6 months } & 49 & $(17.1)$ \\
\hline \multicolumn{2}{|l|}{$\geq 6$ months } & 100 & $(34.8)$ \\
\hline
\end{tabular}

